\title{
Diagnosis and treatment of patients with trigeminal neuralgia
}

\author{
Lins, M.L. A. ${ }^{1}$, Santos, B.G.C. ${ }^{1}$, Bezerra, M. M. G. ${ }^{1}$, Freitas, R. M.L. ${ }^{1}$, Lima, M.A.C. ${ }^{1}$, Arruda, H. S. ${ }^{2}$ \\ 1Estudante do Curso Odontologia - UFPE; \\ 2Pesquisador do Departamento de Embriologia/Histologia - UFPE
}

\begin{abstract}
Introduction: The trigeminal neuralgia is an idiopathic chronic disease known for its intense and unbearable pains. It is associated to the trigeminal nerve which is responsible for the sensation in the face and also motor functions such as the motor control of chewing muscles. The diagnosis is complex and requires a meticulous clinic examination - to be distinguished from others conditions - besides an evaluation of complementary and multidisciplinary exams aiming an effective treatment according to the needs of each patient. Objetives: The purpose of this article is to address the concept of the trigeminal neuralgia, pointing out its etiology, clinical features, diagnosis and treatment methods. Methodology: Several papers concerning the topic of interest were selected and analyzed through the searching means: Google academics, LILACAS and SCIELO. Results: The results show that the first drug chosen for treatment is Carbamazepine. The drug therapy can be broad, depending on each patient. When ineffective, surgical treatment is necessary, which may be by many techniques, with a $73 \%$ rate of positive results. Conclusion: The trigeminal neuralgia is considered the most prevalent and uncomfortable of the neuralgias. According to the analyzed researches, an adequate diagnosis allows an effective treatment.
\end{abstract}

Keywords: Carbamazepine; Diagnosis; Treatment; Trigeminal neuralgia;

*Correspondence to Author:

Lins, M. L. A.

Estudante do Curso Odontologia UFPE

How to cite this article:

Lins, M. L. A., Santos, B. G. C., Bezerra, M. M. G., Freitas, R. M. L., Lima, M. A. C., Arruda, H. S.Diagnosis and treatment of patients with trigeminal neuralgia.International Journal of Pain Research and Treatment, 2018, 1:5

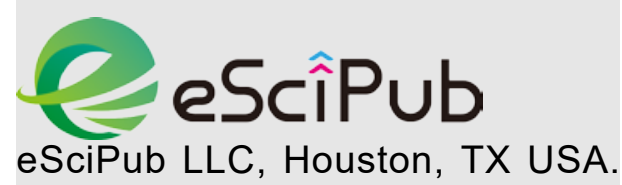

Website: http://escipub.com/ 